\title{
Propostas Para Uma Relação: - Profissionais de Saúde e Mulheres*
}

** Psicanalista; Professora da Escola Nacional de Saude Páblical Fiocruz

"Trabalho originalmente apresentado na 1: Conferéncia $\mathrm{Na}$ cional de Saúde e Direito das Mulheres - 1986 - Brastiia, $D F$.

\author{
Sherrine Maria Njaine Borges** \\ "Escrever é tantas vezes lembrar-se do \\ que nunca existiu" (Clarice Lispector)
}

Sabemos ser condição, no mundo humano, que os acontecimentos vividos só são significativos quando ganham uma possibilidade de serem nomeados, postos em linguagem. E isto é o que nos permite dizer que, também, sofremos do que não se pode dizer. A censura, exercida por um discurso socialmente dominante sobre as mulheres, tende a não deixar lugar para 0 aparecimento do que não entra na coerência própria deste discurso. E os movimentos sociais das mulheres têm o mérito de terem apontado para uma profunda distorção e desconhecimento entre estes discursos e as práticas afirmadas sobre o que são as mulheres e a vida real vivida, dada num determinado contexto social.

Desse novo discurso sobre as mulheres, creio ainda năo podermos avaliar as conseqüências que gera, mas podemos identificar os alvos para onde o combate se dirige. Lutando para desfazer as imagens de "devoção", "sacrifício", "feita para sofrer", "submissa e resignada", "complemento do homem", associadas à maternidade e à vida sexual da mulher, a luta posta em movimento coloca em dificuldades as instituições enrijecidas do casamento, da vida familiar, da educação, da saúde e do trabalho, no que diz respeito aos mecanismos de repetição sem criação dos papéis socialmente esperados para as mulheres.

Os temas privilegiados para a reflexão passam a ser a censura do corpo da mulher, a histeria, a homossexualidade, a depressão, o estupro, o aborto, pois quando as mulheres começam a falar delas, começam a falar de coisas que também não se falam, rompendo o silêncio de vivências encaradas como tabus.

Desse modo, instauram o tempo de falar na 1 : pessoa, desautorizando, assim, o regime de procuração e tutela que historicamente confiscou o que ế da mulher de modo a fragilizá-la, desqualificá-la, impedindo o acesso a si mesma e, conseqüentemente, a outros.

Condenadas por este regime de tutela a interrogar - desejo dos outros para ascender a um fantasma de ser algo conforme os signos destes desejos, as mulheres, de diferentes formas (umas mais organizadas, outras ainda dispersas), não aceitam mais se ausentarem de seu próprio corpo, silenciar sua palavra, negar seu desejo próprio. 
Enfim, da luta contra um discurso autoritário que, reducionista e homogeneizado do que é singular, exclui a diferença, visando ao estabelecimento da igualdade em detrimento da alteridade, do mesmo em detrimento do novo, este meu trabalho inclui uma tentativa mais ampla de muitas mulheres, em diferentes condições sociais, de recuperar esta fala perdida, que se reduziu a um silêncio dos sentidos e dos desejos.

Se sofrermos toda vez que não nos for possivel dar algum sentido coerente com nossa história a algo da ordem do vivido, podemos dizer que, no trabalho em saúde, não se trata de buscar o que se passa no indivíduo em si, mas o que se passa em uma situação dentro da qual este indivíduo está inclứdo (saiba disto ou näo), onde o que interessa não é somente uma situação externalizada num corpo físico, mas aquilo que nesta situação de sofrimento não foi dito, por ser um território proibido, para o sujeito em questão. $\mathrm{O}$ que nos interessa nos modos que as mulheres têm para contornar o que thes fazem sofrer não são tanto os objetos sobre os quais as dificuldades parecem haver-se canalizado, senão uma certa forma de relaçāo das diferentes mulheres com o mundo, com o seu corpo, com sua sexualidade e a de outros, integradas em suas histórias de um modo específico a cada uma. É neste sentido que podemos dizer que se perverte nossa relação de trabalho com as mulheres, toda vez que adotamos uma versão restritiva das possibilidades existentes na vida que é possível para cada um de nós, na relação com os outros e com a sociedade.

Perverte-se justamente porque impede o aparecimento da multiplicidade e variedade de condiçốes que podem ser tidas como satisfatórias por um sujeito. Assim, por exemplo, não basta apenas ter acesso a informaçōes sobre os diferentes métodos anticoncepcionais, é preciso saber se tal ou qual método me permite ou não levar a vida sexual que me é possível, se ele me permite viver o que eu sou. Pois so podemos ouvir do outro aquilo que podemos dizer para nós mesmos.

E sempre por aproximações sucessivas que vamos conseguindo situar o outro/mulher em sua singularidade, em sua diferença e em seu projeto pessoal que o anima e sustenta.

Deste modo, $\varepsilon$ inútil e insuficiente tentar resolver as demandas de saúde das mulheres, de forma abstrata e asséptica, pois se faz necessário tentar encaminhar - que se passa e se fala, dentro de cada situação de: trabalho vivida.

De um modo geral, nossa dificuldade de "escutar" sem expectativa o que o outro vai dizer gera uma situação confusa, onde ora o "social" \&́ usado como bode expiatório, ora é negado, trazendo uma paralisia

Cadernos de Saúde Pública, RJ, 7 (2): 284-289, abr/jun, 1991 
e uma impotência diante da multiplicidade de situaçōes, trazidas de modo avassalador, no dia-a-dia de nosso trabalho em um serviço de saúde. Isto talvez nos ajude a entender por que, muitas vezes, nos vemos fazendo diante de nós mesmos e de outro a quem atendemos um discurso no qual não acreditamos. Por que esta prepotência em nós, de nos iludirmos, se nossos pacientes percebem que, freqüentemente, queremos convencê-los a fazer algo no qual não só não acreditamos, como até, às vezes, sabemos que não produzirá efeito algum?

Parece-me que um ponto de partida imprescindível para que nossos atos tenham eficácia terapêutica é aprender a escutar o que as mulheres falam e como. falam, o que as faz sofrer e as incomoda, como condição para que o profissional de saúde possa, junto a elas, localizar de que forma seu saber específico pode lhes ser útil.

A fragmentaçăo do trabalho socialmente produzida favorece o estilhaçamento do corpo de um indivíduo em mil pedaços, onde os esforços para integrá-lo sâo muitas vezes dificultados pelo próprio profissional que, ao se fixar no seu lugar institucionalizado (médico, psicólogo, enfermeiro etc), impede a circulação de saberes distintos e, também, influencia o modo como as pessoas são recebidas e atendidas em diferentes situações dentro da instituição.

$O$ sofrimento não $\varepsilon$ propriedade de nenhum profissional especializado, e não aparece só na presença destes. Ele faz parte de um modo de viver, possível até o momento por um determinado sujeito, por determinadas marcas de sua história.

Muitas vezes, o sentimento de impotência e fracasso se instala em nosso trabalho, quando confundimos o que são nossos objetivos e limitaçōes com os do outro que nos pede ajuda.

$\mathrm{Na}$ maioria das vezes, a frustração enfrentada, pela evasão, pelo abandono de tratamento, pela nãomudança de situações, dá-se por estarmos, na maioria das vezes, fazendo discursos que são auto-referentes, narcísicos.

A ausência de escuta do discurso do outro, de sua singularidade no sofrimento e de sua demanda, torna a maioria dos atendimentos um grande monólogo.

$O$ outro não se apresenta com algo a ser ouvido e entendido, porque desconhecido por nós, mas sim como o que confirma a minha função, o que ilustra a minha teoria, enfim o que dá aquilo que minha profissão e a instituição dizem que eu sou. Nesse sentido, esta prática de trabalho apresenta-se não só como al tamente frustrante, mas também como uma nova reprodução estéril de modelos que nāo servem para tornar visíveis e possíveis outras possibilidades de trabalho e outras formas de viver. 
Poder escutar o outro, sem preconceitos e pretensões prévias, talvez abra a cada um a possibilidade de legitimar e reconhecer diante dele aquilo que ele mesmo não pode admitir, pensar ou viver - por isto adoece, também.

A ruptura com o discurso auto-referente, narcísico, dá-se no momento em que nos colocamos sob a condição de renunciar a querer aparecer como o que sabe mais sobre o outro do que ele mesmo.

Nesse sentido, clinicar é diagnosticar sem dúvida, comparar o que se tem selecionado de uma organização sintomática com um modelo pré-estabelecido, porém, é também experimentar, quer dizer, fazer existir o que nāo existia, o que não estava dado antes da interiocução, por falta de um interlocutor e de uma escuta diferenciada. $E$ isto se toma possivel quando rompemos a pergunta histérica - onde está aquele que solucionará meu problema para mim?

Porém, numa sociedade auto-referente como a nossa, o gozo chega às vezes a se transformar num dever. $E$, neste imperativo, não pode falhar, não se tolerando nada que possa molestar os ideais construídos socialmente de perfeição, de potência e juventude. O sofrimento, a velhice, a morte se fazem insuportáveis.

Assim, no encontro entre profissional de saúde e cliente/mulher, é necessário descobrir os elementos que facilitem ou bloqueiem este encontro (sempre desigual, mas não impossível), de modo que o que possamos lhe dizer a comova e lhe permita viver o que pode viver e não o que deveria viver, tal como num ideal, fixo e estático, onde muitas vezes nosso desejo se aliena e nos impede de sermos o que podemos ser.

Pode-se dizer que todo método de trabalho em saúde na relação com a mulher (e não so com ela) está na inversão do método médico que só visa a dar ao profissional de saúde possibilidade de "ver o que ele aprendeu a ver", evitando para ele, face a qualquer sintoma ou reaçẩo do paciente, qualquer surpresa desconhecida.

Daí podemos inferir que, para surgir algo novo, para reconhecermos que vemos e escutamos algo novo, ह́ preciso que previamente tenhamos mudado de lugar, do saber a priori, buscando conceitualizar a experiência vivida, a partir dos erros e obstáculos nela vividos, onde a prática clínica nos obriga, constantemente, a refazer o que sabemos, compreendemos ou dizemos, por relação ao paciente, sempre singular, o que é, muitas vezes, diff́cl e doloroso.

A intervenção técnica, seja ela qual for, não tem a função de ser comprovação ou veredito, reduzindo a fala do paciente/mulher a ser uma ilustração das teorias. 
A intervenção introduz uma hipótese, que há de ser experimentada no estudo da resposta que virá do paciente, que nos indicará, paulatinamente, como deve ser e precisa ser tratado. Deste modo, as dimensōes do trabalho em saúde superam, em suas metas, os objetivos terapêuticos que são os primeiros vocabulários de um pedido de tratamento, antes que se desvele a problemática humana propriamente dita.

E nunca é demais lembrarmos que o saber nem sempre é suficiente para se conseguir fazer - especialmente em se tratando de seres humanos -, há algo mais e tem a ver com o profissional de saúde, pois este, durante sua prática pessoal e cotidiana, é levado, mesmo que disso não se dê conta, a retomar contato com "o paciente" que nele existe, isto é, com as etapas desse desespero e dessa importância que é "o estar doente". E isto que the permitirá redescobir uma linguagem esquecida e mutilada nele pela deformaçäo técnica: a linguagem da dor, de sofrimento indizível, do horror da morte, do ódio pela dependência do outro. E são essas palavras que, na sua prática de trabalho em saúde, vão lhe servir ou tornar impossível que ele escute, fale e cuide do seu paciente.

Muitas vezes, fascinados pela observação direta, pelos esquemas teóricos do que "deve ser", desfazemo-nos de nossa história, por ser muitas vezes considerada não-científica. Movidos pelo desejo de evitar suportar a ausência daquilo que seria o indice do nosso sucesso, desfazemos em nós e em nossas pacientes o sentido da construção de uma história.

Assim, o paciente, e em especial as mulheres, longe de nos remeter a uma parte de nós mesmos, torna-se o estranho de quem vamos, de uma forma asséptica e higiênica, observar os sintomas, descrever os comportamentos, à procura de "sinais" de uma doença qualquer.

Tudo o que o paciente/mulher nos disser vai inscrever-se num quadro estranho à sua miséria e drama, onde o observador profissional de saúde já não está mais implicado no diagnóstico formulado. E se nāo há mais lugar entre o profissional e o seu paciente para o imprevisto, não há mais possibilidade para uma relação intersubjetiva, para uma prática transformadora e prazeirosa.

Numa situação em que tudo está previsto antecipadamente, o profissional de saúde nấo corre o risco de se encontrar impotente, questionado e utrapassado nas suas referências (teóricas, técnicas etc). As teorias $\mathrm{e}$ as técnicas, nesse momento, servem-lhe de defesa ou de abrigo. Pois o temor diante de algo năo-previsto, diante de uma intrusão perturbadora por parte do paciente/mulher, pode engendrar no profissional de saúde a busca de uma proteçẩo, e esta pode ligar-se ilusoria- 
mente ao contexto institucional, que deve reassegurá-la através das normas, das rotinas, dos manuais, da autoridade a priori. Énos insuportável a idéia de não sabermos a priori o que surgirá a cada atendimento, seja o primeiro ou não. E-nos insuportável a idéia de admitirmos que pouco ou nada sabemos sobre os sujeitos-mulheres, para os quais nossos serviços se dirigem.

$\mathrm{Na}$ formação do profissional de saúde, cria-se muitas vezes uma situação onde o "não-saber" deste é indispensável, e sua desqualificação em relação à sua história necessária. E o que se exíge do profissional em formaçāo, este exige depois de seu paciente: que lhe dê a onipotência do saber, que se apague como sujeito de uma palavra própria, que elimine o sentido de sua história, gerando, tanto por parte do profissional, quanto do paciente, sentimento de "ser utilizado", "ser pilhado" na sua singulardade.

Essa é uma das razōes que nos permitem dizer que os serviços de saúde e seus representantes expropriam das mulheres a satisfação do controle sobre seus próprios processos, debilitando-a ainda mais, impedindo-a de desenvolver sua capacidade auto-reflexiva sobre os movimentos e sinais do seu próprio corpo e sobre a especificidade de sua sexualidade, que está mais perto das contradiçöes e desenganos do cotidiano, do que de um sonho romântico e idílico.

Negando como se constrói em nós a idéia de ter um corpo humano, as práticas vigentes em nossos serviços de saúde negam, também, que ser homem ou ser mulher, ser masculino ou feminino, ser māe ou pai sāo vivên cias psíquicas construídas socialmente e não meros epifenômenos de uma dada anatomia. Não nascemos homem nem mulher, nascemos com um certo sexo anatômico, e as conseqû́encias disso implicam uma construção, uma história de cada sujeito e de cada sociedade.

\section{REFERÊNCIAS BIBLIOGRÁFICAS}

CATALĀ, Magda, Reflexiones desde un cuerpo de mujer. Anagrama. Barcelona, 1983.

FREUD, Sigmund. Esboço da Psicanálise (1940)

FREUD, Sigmund. O malestar na ctvilizaçäo (1930)

FREUD, Sigmund. Fragmento da análise de um caso de histeria (1905). Imago, Rio de Janeiro, 1974 (Ed. Standard Brasileira das Obras Psicologicas Completas de Sigmund Freud).

LACAN, Jacques. Mais... ainda (Seminário XX). Zahar, Editores, Rio de Janeiro.

LEMOINE, Eugène, Partage des femmes. P.U.F., Paris 1982.

Cadernos de Saúde Pública, RJ, 7 (2): 284-289, abr/jun, 1991 